\title{
Estrategias de comprensión audiovisual y traducción del español al chino en una comunidad fansub
}

\author{
Leticia Tian Zhang \& Daniel Cassany \\ Universitat Pompeu Fabra
}

\begin{abstract}
Documentamos y analizamos una comunidad china de fansub, que traduce y subtitula series y películas hispanas, explorando los recursos y estrategias que se utilizan para comprender y transcribir del español y traducir al chino. Con etnografía virtual (Hine, 200o), combinando observación participante, entrevistas en profundidad y análisis de contenido, los resultados describen una comunidad jerárquica, con normas que regulan los procesos colaborativos de escritura y traducción, que incluyen el uso de estrategias multimodales sofisticadas (empleo creativo de recursos técnicos, lingüísticos y webs, prácticas de translanguaging). La comunidad también desarrolla sus propios criterios sobre lo que es una buena traducción, con roles y actitudes de aprendices serios ante los errores cometidos. Dichas prácticas ejemplifican otras características relevantes de las comunidades digitales (productividad fan, mediación cultural, traducción audiovisual y amateur) y ofrecen recursos interesantes para aplicar a la enseñanza formal de L2.
\end{abstract}

Palabras clave: fansub, comprensión y traducción audiovisual, recursos lingüísticos en línea, translanguaging, español como lengua extranjera

\section{Introducción}

La traducción audiovisual es una actividad lingüística sofisticada por las características del discurso (coloquial, conversacional) y del contexto (pantalla pequeña, velocidad de lectura). Las dificultades se incrementan entre idiomas tipológicamente lejanos, como el español y el chino. Por ello, suelen realizar esta tarea equipos profesionales altamente cualificados, con suficientes recursos tecnológicos y lingüísticos, con unos costes elevados de producción que sufragan las televisiones e, indirectamente, los miles de telespectadores. Pero en las comunidades de fansubbers un grupo heterogéneo de fans o aficionados traducen, de modo amateur, 
gratuito y en línea; no poseen la formación o los recursos de los profesionales, pero aportan su pasión por las obras populares, su interés por la lengua y la cultura del país y su compromiso con la comunidad. Con todo ello llevan a cabo un trabajo colaborativo sofisticado, que produce eficazmente decenas de episodios subtitulados, que agradan a un número creciente de seguidores en Internet.

Conocemos este fenómeno como fansubbing (abreviatura de fan-subtitling en inglés); sus autores son fansubbers, y los productos resultantes, fansubs, son cualquier tipo de obra audiovisual (serie, película, documental). En español también se usa con frecuencia el término anglófono (Ferrer, 2005). Los fansubs suelen distribuirse gratuitamente en la red, puesto que a menudo los originales no están presentes en el país de recepción, y de esta manera los fans pueden disfrutar de una versión subtitulada previa a su traducción comercial.

En China, dada la escasez de audiovisuales hispanos, el fansub se ha convertido en una vía de acceso conveniente -y a veces única- a la cultura hispánica. Gracias a la diseminación de los programas de subtitulación y edición digital, los fansubbers han desarrollado una cadena de trabajo eficiente y cooperativa (DíazCintas y Sánchez, 2006; Martínez, 2010; Zhang y Cassany, 2016). El proceso prototípico empieza con la localización del material original, seguida por su transcripción al idioma original y/o su traducción al idioma de la audiencia, por la sincronización de escritura y vídeo y por la codificación del producto final.

Nos proponemos analizar esta práctica dentro de una comunidad china de fansub, que subtitula series y películas hispanas a su lengua materna. Adoptando una perspectiva émica y centrándonos en dos de las tareas más complejas que desarrollan (transcribir en español y traducir con subtítulos al chino audiovisuales españoles que simulan registros orales rápidos y coloquiales), revelaremos la dinámica de esta inteligencia colectiva (Lévy, 1997), conformada por la aportación de los conocimientos y experiencia individuales, además del trabajo cooperativo. Exploramos los recursos que emplean para comprender el original, las estrategias usadas en la traducción audiovisual, sus criterios personales sobre lo que es una buena traducción, y el mecanismo de revisión del producto audiovisual. Estas prácticas letradas fortalecen su identidad de media fans, como productores, lectores, escritores y, finalmente, consumidores, espectadores y participantes (Jenkins, 1992, p. 208). Asimismo, son cuestiones desconocidas en la mediación españolchino, que tienen mucho interés para el aprendizaje de ELE en contextos digitales e informales (Zhang y Cassany, 2019a, 2019b). 


\section{Estado de cuestión}

El fansub es un ejemplo típico de fan text (fanfiction, fanzines, fan art), objeto de estudio frecuente en la investigación sobre el fandom, el reino (kingdom) de los fans. Sus actividades se caracterizan esencialmente por la productividad y participación (Fiske, 1992; Jenkins, 2006). Aunque el fandom tenga ilustres precedentes históricos y analógicos, la llegada de Internet y de la Web 2.o facilitó su crecimiento global, dando lugar a lo que Hills (2002) conceptualiza fandom justo a tiempo. Adoptando una perspectiva intercultural, los investigadores señalan el empoderamiento personal que implica el fansubbing (Dwyer, 2012), pero también el enfrentamiento que plantea con las industrias culturales (Lee, 2011) y los derechos de autor (He, 2014).

En China, varios estudios valoran este fenómeno como una de las manifestaciones más representativas de la cibercultura (Qiu, 2010; Zhang, 2013) y un ejemplo ilustrativo de la nueva cultura participativa $(\mathrm{Li}, 2015)$. Con una organización jerárquica, los grupos chinos priorizan la eficacia y exigen una actitud seria y una dedicación mínima a los fansubbers (Boyko, 2012). Según Zheng (investigadora de la cultura online que se entrevistó con Jenkins en 2013), los fansubs producidos en China tienen una calidad sorprendentemente buena, gracias a la organización eficaz del trabajo colaborativo, la motivación inherente y la gratificación espiritual que se obtiene.

En segundo lugar, el fansubbing constituye también una manifestación relevante de fantranslation (O'Hagan, 2008). Los primeros estudios sobre subtitulación y traducción comercial resaltan el carácter amateur de los "subtítulos hechos por fans para fans” (Díaz-Cintas y Sánchez, 2006; Pérez-González, 2007), hasta considerarlos un "obstáculo para el traductor profesional" (Ferrer, 2005), pero trabajos generalmente más recientes argumentan que la calidad de ciertos fansubs alcanza casi la profesional o incluso la complementa o la beneficia (Martínez, 2010; Tian, 2011; Tonder, 2015).

En el caso de los fansubs chinos, como mediación entre dos lenguas poco afines, se presta atención al tratamiento de elementos lingüísticos y referentes culturales (Wang, 2014). También se destaca una tendencia a reescribir y manipular sobre los textos, de manera idiosincrásica, creativa y con un "abuso" del humor (Xiu-Xing, 2015). Con ello, los grupos pretenden facilitar la transferencia del contexto extranjero a lo local y familiar, y lograr mayor popularidad entre los espectadores. 


\section{Objetivos}

Nos proponemos explicar cómo los subtituladores de un grupo de fansub chino comprenden y traducen el español coloquial de las series de televisión hispánicas. Para ello, establecemos los siguientes objetivos específicos:

1. Describir la composición y la cadena de trabajo del grupo.

2. Documentar, describir y analizar las tareas de transcripción y traducción: los criterios generales, los recursos (extra) lingüísticos usados, el control de calidad del producto, etc.

3. Explorar las implicaciones de la práctica lingüística cooperativa para el aprendizaje.

\section{Marco teórico}

A diferencia de las comunidades de fansubbers o de sus productos lingüísticos, las prácticas de comprensión audiovisual en L2 que realizan los fansubbers no han merecido ningún estudio hasta el momento. Nos situamos en este marco y utilizamos este término para describir la práctica de comprender un discurso (película, serie, reportaje) que transmite datos simultáneamente por el modo oral y el visual (Casañ, 2016) y que presenta notables diferencias con la comprensión cara a cara convencional: (1) son discursos reconstruidos, con actores, guiones previos y escenarios simulados (sitcom, fantasía, ciencia ficción, dibujos animados); (2) presentan hablas fingidas (sobreactuadas, simplificadas, infantilizadas); (3) son discursos grabados, cosificados y comercializados, disponibles en cualquier lugar y momento; (4) son productos manipulables (podemos pararlos, retroceder y revisualizar varias veces una secuencia, o activar el zoom para aumentar un fotograma); (5) se ofrecen versiones subtituladas o dobladas en varios idiomas, de modo que la audiencia puede elegir las combinaciones lingüísticas que faciliten la comprensión; (6) son productos digitales, distribuidos por internet, que permiten consultar la red para hacer búsquedas de dudas, consultas culturales, etc., y (7) existen comunidades de fans para algunas obras que ayudan al espectador novato o con dificultades para comprender, con varios recursos (repositorios de obras, foros de consultas, diccionarios, etc.). Considerando que el consumo de audiovisuales en L2 es cada día más frecuente, creemos que esta práctica particular de comprensión auditiva merece estudios específicos.

Por último, como los fansubbers son a la vez subtituladores-traductores y aprendices de español, participan de manera natural en contextos de aprendizaje situado (Wenger, 1998), como miembros de una comunidad de práctica (Liu y de 
Seta, 2014; Wenger, 1998). Además de proporcionar un ímpetu tangible a las actividades de traducción, el fansubbing también promueve la autonomía del aprendiz, brindándole oportunidades de participar en el aprendizaje colaborativo y la negociación del significado (Lakarnchua, 2015). De acuerdo con Barton y Lee (2013), dicho proceso empieza a menudo con un propósito particular (ej. revisar el subtítulo), implica la cooperación en la comunidad, y supone la reformulación constante de los productos.

\section{Metodología}

\subsection{Diseño del estudio}

Nuestro estudio es cualitativo, émico y participativo. Considerando el contexto digital en que emergen las culturas y comunidades fan, adoptamos la etnografía virtual (Hine, 2000), cuyos principios metodológicos adaptan la aproximación tradicional de esta metodología a la red, sin descuidar las (dis)continuidades con el espacio físico; es decir, todas las formas de interacción son etnográficamente válidas, no solo las que implican una relación cara a cara (ibid.). Siguiendo esta disciplina, pretendemos documentar, comprender e interpretar las prácticas audiovisuales de los agentes participantes, poniendo especial atención en las herramientas tecnológicas que utilizan y las interacciones dentro del grupo. Nos basamos en un estudio preliminar sobre la comunidad de fansubbers chinos (Zhang y Cassany, 2016), que describe su organización, los roles que ejercen en el proceso de traducción y las normas éticas que comparten sus miembros. Aquí ampliamos y profundizamos aquella perspectiva, centrándonos en el análisis y la documentación de las estrategias empleadas por los subtituladores y los traductores.

\subsection{Campo y participantes}

El campo de estudio, al que denominaremos “The Burrow” (TB), surgió por muestreo de conveniencia: la informante principal (a quien llamaremos Kiwi) es conocida de la primera investigadora y coincidió con ella en Barcelona (España) en el momento del estudio. Una primera entrevista exploratoria con ella confirmó que se incorporó al grupo en 2013, trabajó sucesivamente como transcriptora y traductora, y que luego asumió funciones de dirección de uno de los subgrupos. Asimismo, varias búsquedas en la red (con Baidu) comprobaron la idoneidad de esta comunidad, como objeto de estudio: (1) TB cuenta con un subgrupo específico para series y películas hispanas, lo cual se ajusta a nuestro interés investigativo; (2) 
el grupo tiene entrada en Baidu Baike, según la cual tiene más de 6 años de historia y una alta productividad (ej. 9 series subtituladas, correspondientes a 328 episodios; 13 series en curso en varios idiomas; 40 películas), y (3) TB disfruta de un número estable y elevado de seguidores (varios miles), que muestran su apoyo con comentarios positivos, reenvíos o "Me gusta" en distintos foros, lo cual populariza mucho el grupo en la red., ${ }^{1,2}$

Elegimos el subgrupo que dirige Kiwi, compuesto por 27 personas, que subtitulan una serie de televisión española popular, como subcampo de observación y estudio. La mediación de esta informante principal facilitó nuestra entrada a la comunidad y el contacto con dos participantes e informantes secundarios relevantes, elegidos por su representatividad y complementariedad: el subadministrador de idioma español (Moisés) y el administrador general (Shin). Los tres participantes ocupan puestos a varias escalas, lo cual permitió conocer las distintas esferas de la comunidad. Su guía también orientó la recogida de datos, puesto que pudimos aprovechar su experiencia, habilidades y conocimiento del grupo de fansubbers.

\subsection{Recogida de datos}

\subsubsection{Procedimiento}

Gracias a la mediación de Kiwi, realizamos otra entrevista exploratoria con el administrador Shin. Siguiendo su consejo, entramos en la comunidad como una fansubber cualquiera, para no molestar a otros miembros mientras emprendíamos las tareas de campo. Nos sometimos al proceso ordinario de reclutamiento: realizamos un test inicial de transcripción en español y, con la calificación positiva, accedimos a los grupos de chat en QQ (mensajería instantánea china), a uno de los subgrupos hispánicos y al subgrupo particular que coordina Kiwi y que habíamos elegido como objeto de estudio. Con ello quedamos incluidos oficialmente como miembros de TB. También obtuvimos los consentimientos éticos de los tres informantes básicos del grupo.

A partir de febrero de 2016, hemos participado activamente en las tareas de subtitulación, en las reuniones mensuales en línea y en las conversaciones en chats. Teniendo en cuenta los consejos formulados por Li (2015), también procuramos mantener una actitud sincera y humilde, respetando las normas y valores propios de la comunidad. Esto posibilitó adoptar una visión émica y poder

1. http://www.baidu.com/. Es el motor de búsqueda más popular en idioma chino.

2. https://baike.baidu.com/. Es la enciclopedia colaborativa en línea más grande en idioma chino. 
realizar una triangulación metodológica, con las que llegamos al corpus, muy amplio y heterogéneo, recopilado de manera cíclica (Androutsopoulos, 2013) durante 7 meses, que presentamos en el siguiente apartado.

\subsubsection{Instrumentos}

Tabla 1. Instrumentos y datos recogidos

\begin{tabular}{|c|c|}
\hline Instrumentos & Datos recogidos \\
\hline $\begin{array}{l}\text { Observación en } \\
\text { línea }\end{array}$ & $\begin{array}{l}162 \text { documentos multimedia generados por miembros del grupo [sitios y } \\
\text { páginas web, episodios y películas subtitulados, normas y declaraciones } \\
\text { grupales, capturas de pantalla] }\end{array}$ \\
\hline $\begin{array}{l}\text { Observación } \\
\text { participante }\end{array}$ & $\begin{array}{l}31 \text { artefactos multimodales producidos como fansubber [correos } \\
\text { electrónicos y test, vídeos originales, subtítulos e historial de chat] }\end{array}$ \\
\hline $\begin{array}{l}\text { Entrevistas } \\
\text { semiestructuradas } \\
\text { en profundidad }\end{array}$ & $\begin{array}{l}3 \text { entrevistas presenciales con Kiwi ( } 3 \text { horas); } 4 \text { y } 3 \text { en línea con Shin (7.138 } \\
\text { caracteres) y Moisés ( } 1.941 \text { caracteres, } 13 \text { imágenes). }\end{array}$ \\
\hline $\begin{array}{l}\text { Conversaciones } \\
\text { asíncronas por } \\
\text { chat }\end{array}$ & $\begin{array}{l}55 \text { temas de conversaciones asíncronas con los } 3 \text { informantes [7.056 } \\
\text { caracteres, } 4.190 \text { segundos de mensajes de voz y } 4 \text { imágenes] }\end{array}$ \\
\hline Notas de campo & 30 páginas manuscritas de DIN A4. \\
\hline
\end{tabular}

* Para calcular el volumen de este corpus con referentes occidentales, anotemos que los caracteres son ideogramas y que se suele considerar que un carácter chino equivale a 1,5/1,8 palabras del inglés.

Dada la conveniencia geográfica con la informante principal, combinamos las técnicas de la etnografía convencional y virtual en la recogida de datos. Por un lado, realizamos entrevistas semiestructurales cara a cara con Kiwi, en un ambiente relativamente informal, con listas de preguntas preparadas anteriormente a base de la observación en línea, lo cual facilitó la comunicación y un mayor grado de desenvolvimiento. Por otro lado, empleamos la observación en línea para recuperar datos archivados, y la observación participante para obtener datos elicitados trabajando como transcriptora.

Asimismo, nos basamos en la metodología responsiva (Barton, 2007; Stringer, 1999), que permitió adaptarnos al grupo, a sus hábitos y preferencias acerca del uso de chat. Por ejemplo, cuando surgía alguna pregunta puntual en nuestra investigación, dejábamos un mensaje por QQ o su equivalente Wechat al informante, quien lo respondía cuando le convenía e incluso enviaba mensajes de voz y capturas de pantalla para facilitar la comprensión. De cara a los objetivos de este artículo en particular, priorizamos la interacción con Kiwi y Moisés, puesto que conocen y dominan mejor las tareas lingüísticas. 


\subsection{Análisis de datos}

Digitalizamos y organizamos los diferentes componentes del corpus (notas manuscritas, capturas de pantalla, texto en varios formatos) para conservarlo, contabilizarlo y analizarlo. Para las conversaciones mediadas por móvil, aprovechamos la función de la propia app y las exportamos a historiales de chat aptos para guardarse en el ordenador. Procesamos el corpus con las lenguas originales (chino, ocasionalmente español e inglés), pero desarrollamos el análisis en español, por lo que los datos citados en adelante obedecen a las traducciones propias.

Iniciamos un análisis preliminar y cualitativo de contenido (Cáceres, 2003), identificando prácticas letradas y temas recurrentes. Clasificamos los datos según las categorías propuestas por Barton (2007) y Hamilton (2000), ya aplicadas al estudio de otra comunidad de fans traductores en Valero-Porras y Cassany (2016): (1) participantes, sus roles y sus relaciones; (2) entornos donde tienen lugar; (3) propósito y ámbito social; (4) artefactos y herramientas; (5) actividades; (6) valores, creencias y actitudes; y (7) rutinas, normas y patrones de comportamiento.

Los resultados del Apartado 4.3. y 4.4. (Recursos de comprensión audiovisual y transcripción) surgieron de manera inductiva al relacionar datos aparentemente dispersos pero interconectados: una conversación en chat sobre la técnica de disminuir la velocidad de reproducción y un tutorial elaborado por el grupo que aconseja el uso del portugués como lengua de mediación. Recabamos más datos sobre las técnicas de transcripción y traducción en las entrevistas posteriores con Kiwi y Moisés. Finalmente elaboramos el listado de recursos con descripciones lingüísticas generales y algunos ejemplos representativos.

Los resultados de los apartados 4.4.2 (Traducir al chino), sobre características de la traducción, y 4.5. (Errores), sobre análisis de errores y procedimientos de corrección, se inspiran en trabajos previos del fansub chino de cariz traductológico o intercultural (ej. Li, 2015; Tian, 2011). Nuestra aportación radica en abordar estas cuestiones para la combinatoria español-chino, que resulta novedosa y necesaria. Para el Apartado 4.5 catalogamos y analizamos los errores más frecuentes de este tipo de traducción audiovisual, a partir de un corpus de 106 capturas de pantalla de vídeo, con errores lingüísticos, que facilitó la informante Kiwi. Nuestro análisis detecta el tipo de conocimiento lingüístico en el que se comete el error, su causa y las posibles soluciones. 


\section{Resultados}

\subsection{La comunidad}

Creada en 2012, TB se dedica a traducir principalmente telenovelas y películas en inglés y español; entre su producción hispánica destacan series clásicas de tipo Física o Química (España) o Yo soy Betty, la fea (Colombia). El grupo prioriza la calidad del producto (rigor y coherencia de subtítulos y traducción) a la rapidez de actualización (publicar series de moda al poco tiempo de emitirse en los países de origen).

TB se estructura jerárquicamente (Figura 1), con unos 250 miembros activos repartidos en tres subgrupos: español, inglés y postproducción. El "subgrupo español" constituye la mitad de la comunidad ( 125 miembros), con fansubbers de China continental y Taiwán, además de un español y una colombiana; la mayoría viven en China, pero también hay estudiantes y trabajadores en Europa y América Latina. Según el administrador Shin, los subgrupos español e inglés siguen el mismo proceso de subtitulación y traducción de originales hispanos o anglófonos, respectivamente, y el tercero se encarga de componer los complejos productos multimodales de salida (con un audio en español, subtítulos en español en alfabeto latino y traducción al chino con sinogramas).

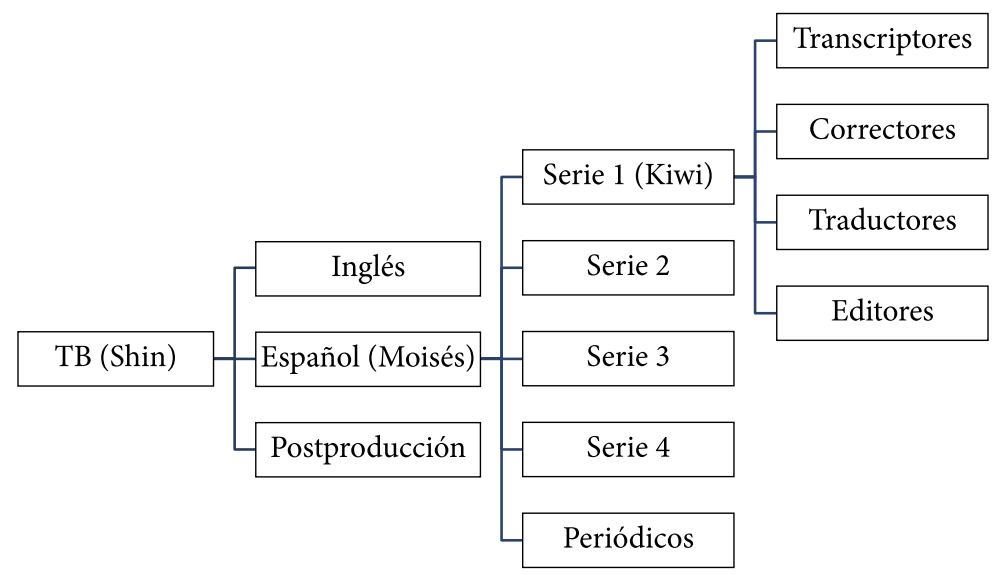

Figura 1. Composición de la comunidad (elaboración propia) 


\subsection{Normas generales}

Veamos primero las normas públicas, establecidas por la comunidad, que deben cumplir todos sus miembros y que regulan y estandarizan aspectos lingüísticos y formales de la subtitulación:

1. Transcribir todos los diálogos, canciones y textos figurados de cada escena, cuando sean medios de expresión, usando estrictamente la escritura española. Evitar los nombres de caracteres y las descripciones de situaciones (ej. "Peter:" o "suena el despertador").

2. Contextualizar la transcripción con puntuación (ej. añadir “i!” o “ ¿?” a la interjección usual "eh" según el contexto; “...” a vacilaciones e interrupciones, y “\#\#" a las letras de canciones), con repeticiones (ej. se registra la risa con "jaja” o "jajaja” según duración) y con selección (ej. se incluyen solo el argumento principal cuando hay varias voces simultáneas).

3. Respetar el máximo de 65 letras/línea; separar frases en caso de exceso de palabras (fenómeno frecuente en español) según la pausa, la entonación, la aparición del "y" o la gramática.

Para la traducción al chino hallamos:

1. Conservar los signos de puntuación que manifiestan emociones $(i !, j$ ? , .. y :) y sustituirlos por equivalentes chinos (ej. “!”, “?”). Omitir el resto (punto, coma), que es menos relevante, y reemplazarlos por un espacio. Se agrega “_” para identificar el discurso de cada personaje cuando puede haber confusión.

2. Mantener los antropónimos, para evitar complicaciones en la traducción colaborativa; traducir los topónimos comunes con la forma usual (ej. la traducción de “-Andrés, ¿a dónde fuiste? -Madrid." es “- Andrés 你去哪儿了 (ni qu na’erle) ? -马德里 (madeli)”).

3. Respetar el máximo de 18 caracteres/línea (o 4 caracteres/segundo) y modificar la longitud de la traducción según el tiempo que ocupa el original para acomodar la visualización global.

4. Unificar a un estilo conciso y claro, con recreaciones ocasionales de estilos específicos (ej. lenguaje vulgar para personajes de clase baja). No traducir las interjecciones propias ("eh", "ah", "oh") cuando las transmite el vídeo y resultan redundantes. 


\subsection{Recursos de comprensión audiovisual y transcripción}

La transcripción es probablemente la tarea más complicada y relevante, considerando la rapidez e implicación del habla de las series españolas, con registros coloquiales, vulgares, profesionales o formales. También resulta esencial para proceder con éxito en los siguientes pasos de la cadena: cualquier error de transcripción tiene consecuencias graves en el resto de pasos (traducción, sincronización). Para realizar esta tarea los fansubbers aprovechan su competencia lingüística alta (demostrada con un test de acceso a la comunidad) y emplean varios recursos de comprensión oral que aprenden con la práctica y que comparten con la comunidad. Hemos hallado 7 prácticas:

\section{Disminuir la velocidad de reproducción}

Se usa ampliamente entre los fansubbers; se aplica directamente sobre el reproductor del vídeo equipado con esta función (ej. Storm Codec Baofeng, QQ Media Player, VLC) para visualizar el original a una velocidad inferior a la normal, como o,7 sobre 1. Según los entrevistados, así es más fácil completar la transcripción de algunos elementos del discurso, como artículos, pronombres y preposiciones, que a velocidad normal pueden pasar desapercibidos. También permite captar algunas sílabas principales de las secuencias incomprensibles, lo cual ofrece más posibilidades de poder relacionarlas entre sí, deducir las palabras completas e inferir su significado, con la ayuda del contexto verbal o no verbal. En una reunión grupal unos miembros comparten sus experiencias con esta técnica:

Seudónimo 1: Qué hago si no puedo entender lo que dice QAQ (emoji)

Kiwi: Yo en esa situación suelo bajar la velocidad hasta $0,9 \ldots$ a veces incluso o,6 (carita de llorar)

Seudónimo 2: El trabajo del corrector es muy muy rápido

Seudónimo 1: Normalmente tampoco lo consigo si bajo la velocidad (carita de llorar)

Seudónimo 3: Había una vez que con o,5 aún no entendí... jaja qué historia más triste

Kiwi: ¿Y al final qué hiciste?

Seudónimo 3: De hecho si la bajas se siente que cambia un poco el tono

-: Suena raro

-: Pues adivinar... y marcarlo para el corrector

[...]

Kiwi: Sí sí, marcarlo primero, y luego ver la traducción y la edición probablemente alguien de repente lo entiende 


\section{Reconstruir el contexto e hipotetizar}

Los transcriptores reconstruyen el contexto general de cada situación a partir del argumento o resumen de cada episodio o temporada, encontrados en la red. También utilizan el cotexto discursivo ya transcrito, previo y posterior, así como los elementos multimodales del vídeo (gestos, miradas, situación), además de las sílabas recuperadas con la estrategia anterior, para hacer hipótesis sobre las palabras usadas en cada fragmento incomprensible, como explica Kiwi:

Hacemos todo lo posible para entender lo que dicen, (observando) inclusive el gesto de los actores, su tono, expresión facial. [...] Es decir, ¿de qué diablos está hablando ese tío? ¿En qué está pensando? ¿Qué haría?

Algunos miembros tienen suficiente competencia lingüística en español para desarrollar dicho proceso mentalmente; otros usan el diccionario españolchino Eshelper para traducir una hipótesis del chino al español y luego verificar si la equivalencia que da el diccionario se corresponde con el audio del vídeo. No obstante, los diccionarios digitales entre el chino y español pueden ser bastante torpes, por lo que esta estrategia requiere una verificación cuidadosa, además de la necesidad de recurrir a otros recursos.

3. Usar los "avisos" monolingües de Wordreference

Los fans emplean la sección "Español: definición" de esta web para identificar un lema completo a partir de unas sílabas, una palabra fragmentada o un deletreo erróneo (Figura 2). El transcriptor teclea en el campo del buscador lo que ha escuchado (la sílaba aproximada o supuesta) y la ventana de "aviso" con sugerencias de Wordreference ofrece diversas opciones de subsanación. Revisando estas propuestas, el transcriptor consigue localizar la palabra registrada. En comparación con otros diccionarios en línea (ej. DRAE), Wordreference provee más posibilidades y a menudo acierta con la opción usada en el vídeo. Por ello los fansubbers valoran mejor este recurso. Además, Wordreference busca dichos o jergas y tiene foros abiertos con comentarios con preguntas y respuestas, lo que no suele darse en otras plataformas.

\section{Usar Google Search}

Los fans utilizan este motor de búsqueda de dos maneras. La primera se asemeja al empleo de Wordreference del punto anterior: las opciones de autocorrección de las palabras tecleadas con el menú de "autocompleción" permiten corregir y afinar la palabra o expresión buscadas (Figura 3). La segunda estrategia se emplea solo si han fracasado las anteriores y consiste en examinar los resultados de la búsqueda para hallar usos similares. Los fans tienen cierta experiencia en ello y han llegado a establecer algunos criterios de selección, 


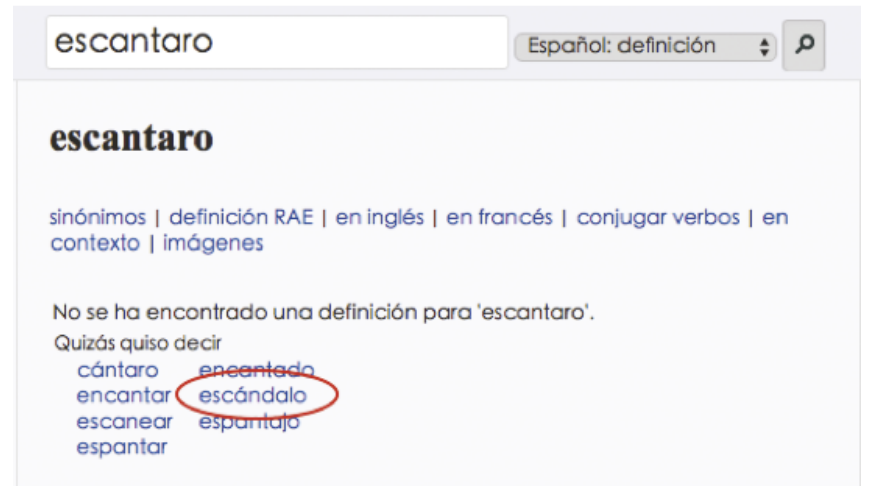

Figura 2. Uso de Wordreference ofrecido por Moisés

para garantizar la fiabilidad: priorizan los enlaces a diccionarios y traductores, así como a sus foros, y después los sitios oficiales o no comerciales (con la URL acabada en: .es, .gobierno u .org).

No obstante, el uso de Google está limitado en la China continental a causa de la censura. Solo se accede con técnicas costosas y sofisticadas (ej. la Red Privada Virtual). Por tanto, los fans que viven allí tienen que manejar también estos medios si quieren aprovechar el motor de búsqueda.

\begin{tabular}{l|l|l|} 
Google & al fin y al pabo \\
$\begin{array}{l}\text { al fin y al cabo significado } \\
\text { al fin y al cabo en ingles } \\
\text { al fin } \mathrm{y} \text { al cavo } \\
\text { al fin } \mathrm{y} \text { al cabo sinonimos }\end{array}$ \\
\hline
\end{tabular}

Figura 3. Uso de Google Search con el menú de "autocompleción"

\section{Usar un tercer idioma}

Siempre que sea posible, los fans buscan en la red subtítulos paralelos o de otros idiomas de la obra en que trabajan, con el fin de facilitar la transcripción al español. En un documento titulado "Observaciones para transcriptores año 14 ", se introducen los siguientes recursos y se indica su uso apropiado:

Aquí va el link de la página principal de la serie en viki:

[...] Viki es un sitio web que enfoca la subtitulación en varios idiomas. Son hechos por fans. [...]. Principalmente en inglés y portugués, que a menudo son traducciones no literales. Pueden servir de referencia, porque si la raíz es la misma se puede deducir el vocabulario español. 
Aquí va la página de YouTube donde está colgada la versión televisiva subtitulada en portugués con pistas originales de la serie:

[...] Personalmente creo que la exactitud de este subtítulo es sobresaliente, ya que fue la televisión quien lo produjo comprando los derechos de autor. Si tenéis nociones básicas del portugués lo podéis aprovechar.

Pero tened en cuenta que son datos relacionados con el subtítulo. Por favor, no los toméis como el original para evitar problemas en la concordancia temporal.

Aunque este tutorial cite solo el inglés y el portugués, se pueden usar otras opciones lingüísticas dependiendo de la condición de acceso y los conocimientos de cada fansubber. Si bien el inglés es la segunda lengua para la mayoría de los chinos, se emplea menos en el fansubbing hacia el español, porque frecuentemente los subtítulos son paráfrasis, que ayudan menos a rastrear el texto literal del original. En cambio, muchos fansubbers prefieren el portugués, que consideran un recurso potente para subtitular, al ser una lengua cercana al español y permitir deducir sin grandes dificultades el texto original. Como explica el tutorial citado, la comunidad ha conseguido acceso a una versión subtitulada en portugués de la serie en cuestión.

En concreto, el protocolo de trabajo consiste en que el transcriptor -que no necesariamente sabe portugués-, teclee algún fragmento del subtítulo portugués que ve en el vídeo (en YouTube o en viki) en algún motor de traducción (Google Traductor), atendiendo las sugerencias de corrección sobre las letras portuguesas (ej. ç, ã) que no tiene el teclado chino, para buscar la traducción al español (Figura 12 y 13). A veces este paso precede a la visualización de la escena, para simplificar la tarea: el transcriptor pasa directamente a corregir la diferencia entre el audio escuchado y la traducción al español que ofrece el motor desde el portugués. Pero esa traducción puede deberse a alguna paráfrasis o equivalencia traductológica del original o a algún error, de modo que las dos formas no coinciden. Ello exige a menudo que el transcriptor preste atención a las distintas formas de expresar el mismo significado en español, como explica Kiwi:

Con el traductor ya sabes más o menos la idea, pero a veces, por ejemplo, el protagonista dijo "me da igual", pero la traducción te sale "no importa". Entonces tienes que pensar mentalmente cuáles son las otras maneras de expresar "no importa", que puedan corresponder con lo que has escuchado. Esto también pasa con las oraciones enunciativas en portugués ("me levanto"), que puede ser "levanto-me". Hay que prestar atención a las diferencias. 
Del mismo modo, en esta captura de pantalla (Figura 4 y 5 ) también notamos este contraste entre el subtítulo y el original. El protagonista dice "Si realmente quieres casarte con él, no le digas nada", mientras la traducción ha cambiado la $2^{\mathrm{a}}$ persona en la $3^{\mathrm{a}}$, por lo que el transcriptor tiene que corregirlo.

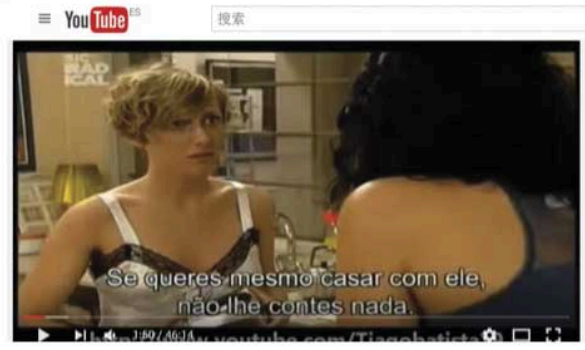

\section{Google}

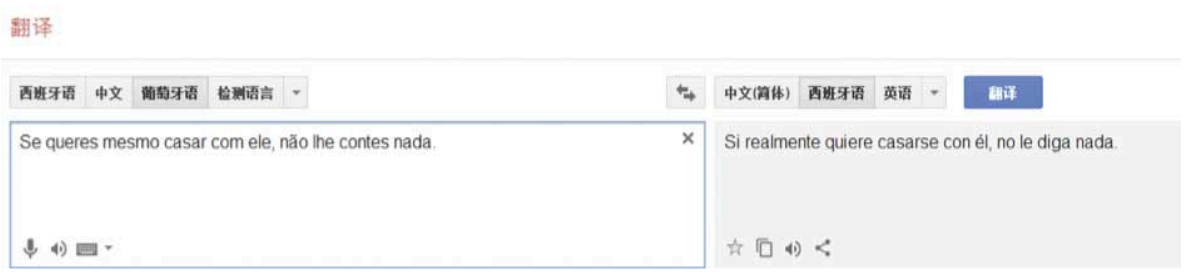

Figuras 4 y 5. Uso de portugués ofrecido por Kiwi

\section{Usar Closed Caption (CC)}

Los fans aprovechan a veces el CC o subtitulado oculto de una obra (escritura que describe la emisión oral), producido habitualmente por televisiones institucionales para las personas con deficiencias auditivas o para espectadores que quieran visualizar la obra en silencio por varios motivos (entornos ruidosos, aprendizaje de lenguas, etc.). El CC suele incluirse en los DVD comercializados y a veces los fansubbers procuran comprarlos (ej. mediante el ebay de España), cuando es posible, para completar la transcripción. Sin duda, el CC facilita la transcripción, pero también exige realizar numerosas modificaciones sobre la escritura y completar huecos.

7. Ayuda de miembros o amigos hispanos

Cualquier duda surgida durante la subtitulación se pregunta en el chat de la serie correspondiente, que funciona como un "servicio 24 de horas" (ValeroPorras y Cassany, 2016). Los miembros hispanohablantes (un español y una colombiana) se encargan de transcribir o corregir series que carecen de referencias de subtítulos, mientras que los fans que viven en países hispanohablantes buscan la ayuda de amigos, compañeros de piso o de trabajo, que sean 
nativos; pero a menudo ellos tampoco son capaces de entender todo el original, sin conocimientos previos del contexto o por ser hablantes de otra variedad dialectal. Según Kiwi, los jóvenes españoles parecen ser los mejores colaboradores para descifrar el original, probablemente por la afinidad cultural:

Bueno mejor preguntar a los nativos (de España). Ahora mi compañera de piso es de Perú, y antes tenía otra mexicana, pues les preguntaba, y a veces ellas tampoco entienden, es que la gente de aquí habla en otra forma, tan de prisa, mascullan y arrastran las palabras... Es súper difícil de adivinar. [...] Los españoles seguro que entienden más, y los jóvenes también, porque esas telenovelas tienen mucho vocabulario coloquial y juvenil, que no utilizan los mayores.

\subsection{Herramientas y características de traducción}

Si el audio se ha transcrito de manera completa, correcta y comprensible, la tarea del traductor -que suele ser un fan diferente del transcriptor- resulta más fácil, porque no busca la exactitud o el detalle del original, sino más bien la recreación del sentido y del contexto del discurso. Su trabajo consta de dos pasos: debe comprender el discurso audiovisual completo (audio y transcripción en español, elementos multimodales) y debe buscar una transferencia lingüística al chino escrito, tratando adecuadamente las diferencias léxicas, gramaticales y sintácticas, además de los referentes culturales (nombres propios, dichos, juegos de palabras).

\subsubsection{Comprender el subtitulado español}

Para ello utiliza estos recursos digitales:

1. Diccionarios y traductores monolingües (ej. DRAE, Wordreference "Español: Definición", wiktionary "español"), bilingües (e.j. Eshelper, Linguee "españolinglés") y multilingües (ej. Google Traductor)

Las herramientas monolingües se emplean para entender las palabras o frases desconocidas, que es el problema más frecuente de los traductores. Aquí resulta muy útil Wordreference, porque permite realizar búsquedas directas de dichos y refranes o consultar y preguntar en su foro. Se puede llevar a cabo la traducción a partir de las explicaciones y ejemplos detallados de estos diccionarios, pero a veces se utiliza el diccionario bilingüe español-chino, que también se puede usar como traductor. En ocasiones el traductor recurre a la intermediación de un tercer idioma (inglés) para traducir entre dos idiomas lejanos. (Cabe considerar que el inglés tiene mucha más historia traductológica con el chino, con mejores recursos lingüísticos.) 
2. Google Imágenes.es

Los fans usan este recurso para visualizar el vocabulario español desconocido que no se deduce por el contexto. Es una estrategia útil con objetos que adquieren denominaciones particulares en la sociedad china o hispana: comidas, costumbres, utensilios de casa, etc. Moisés recuerda el caso de "maracuyá” (Figura 6) y sugiere además que si Google no da buenos resultados, los fans aprovechan Baidu Images (motor de búsqueda chino con funciones similares de Google Imágenes), que permite identificar la imagen y localizar la palabra china equivalente (Figura 7).

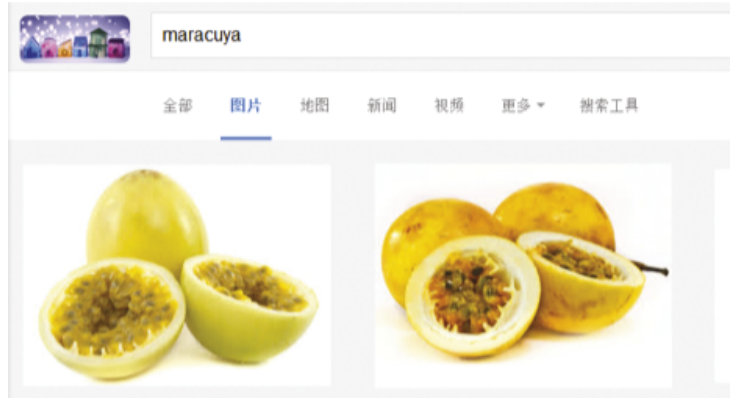

Figura 6. Maracuyá en Google Imágenes

\begin{tabular}{|c|c|c|}
\hline 氞片 $\widehat{O S}$ & @ & 百度一下 \\
\hline
\end{tabular}

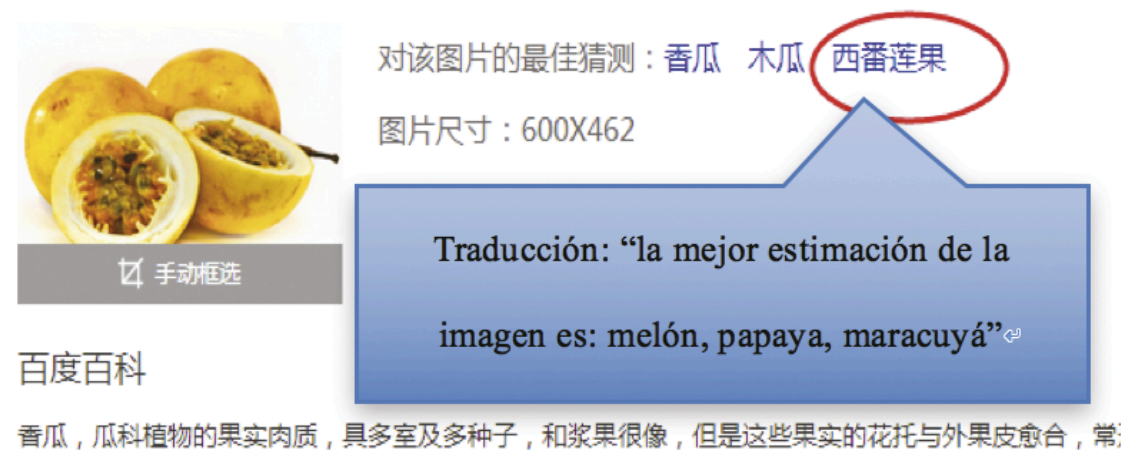

Figura 7. Reconocer maracuyá en Baidu Images

\section{Wikipedia}

Los fans entrevistados dicen utilizar las entradas de Wikipedia en varios idiomas como un recurso de traducción, puesto que la mayoría de artículos están editados en varias lenguas y aportan información parecida o incluso igual. 
En concreto, utilizan de modo comparativo las páginas en español, chino e inglés, si están disponibles (Figura 8 y 9). Es un recurso eficaz sobre todo con nombres propios $\mathrm{u}$ otras expresiones empleadas en la cultura hispánica, que a veces tampoco se entienden por su definición o por la visualización.

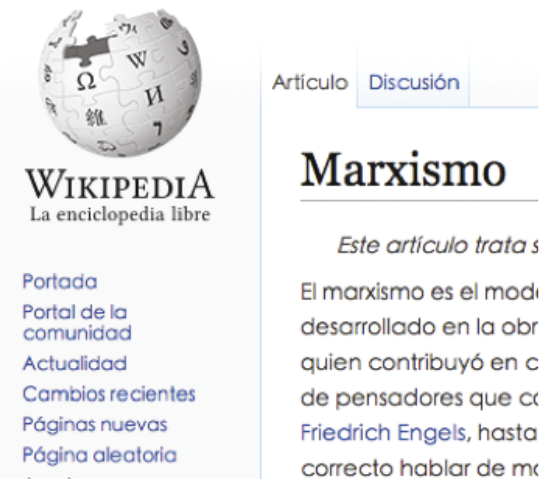

Figura 8. "Marxismo" en Wikipedia española

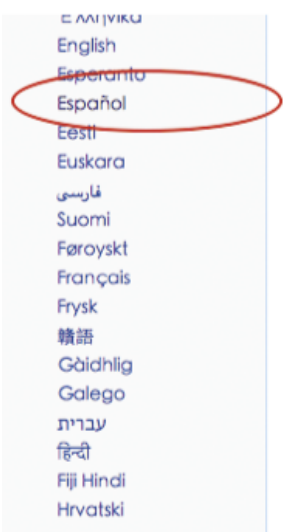

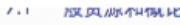

9.2 马克思主义网站

概念 [ 编辑]

古典马克思主义指的是由卡: 照. 即使在马克思在世时, 1 的顺风车”，并且说 “如果1

历史唯物主义 [ 编辑 ]

“社会不是由个体构: 一卡尔·马克

历史唯物主义又被爱德华. 一个社会的基本特色（社会| 律系统则构成上层建筑, 底|

Figura 9. "Marxismo" en Wikipedia china

4. Subtítulos en inglés

Un último recurso de traducción consiste en recurrir a subtítulos en inglés hechos por fans, como los disponibles en Viki Subtitling Community. Suelen ser traducciones no literales, con paráfrasis o síntesis, que ofrecen pistas y referentes a los miembros competentes en esa lengua, sobre todo con los dichos difíciles en el diálogo. 


\subsubsection{Traducir al chino}

Para entender mejor el uso de estas estrategias resulta útil conocer la concepción de "buena traducción" que han desarrollado los fansubbers. Los tres criterios fundamentales son: (1) evitar los errores lingüísticos más corrientes (ver Apartado 4.5); (2) preservar el estilo del original, que suele ser diálogo coloquial -aunque ocasionalmente puede variar según la escena y el personaje-, y (3) valorar la libertad y creatividad del traductor para reproducir algún contexto particular o el sentido específico de una expresión idiomática o una idiosincrasia hispánica para la audiencia china. Como explica Kiwi: "nuestra traducción pretende ofrecer a los espectadores chinos la misma experiencia que pueda tener un nativo". Para lograrlo se aplican las estrategias traductológicas generales como la reducción (ej. algunas interjecciones y los cliché de cortesía) y la expansión (ej. "Felipe VI" es traducido en "el rey Felipe VI"); también se emplea la adaptación (Tomaszkiewicz, 1993) de manera libre e inteligente, para localizar o domesticar el original mediante su vinculación con algunos elementos familiares para los espectadores chinos:

\section{- Chengyu (成语)}

Son proverbios chinos; contienen entre cuatro y siete caracteres y condensan un pensamiento o una historia de la cultura antigua. En la subtitulación resultan útiles porque: (1) no superan el número máximo de palabras disponibles por fotograma; (2) evocan alusiones históricas chinas, que sitúan lo occidental en un contexto oriental auténtico (Li, 2015).

El ejemplo de abajo (Figura 10) ilustra la utilización de tres proverbios 上刀 山下油锅 (shang daoshan xia youguo) ("subir a la montaña de cuchillos y bajar a la sartén ardiente”), 两肋插刀 (lianglei cha dao) ("introducir cuchillos en las dos costillas") y 在所不辞 (zai suo buci) ("nunca jamás se cede"), que suelen emplearse conjuntamente para expresar la disposición y el sacrificio para una misión. El segundo, procedente de una historia antigua sobre un héroe del pueblo que murió por su amigo; recuerda especialmente la fraternidad y la lealtad incondicional. Observamos que con estos proverbios cultos, los fans se alejan del criterio de fidelidad en la traducción; no obstante, consiguen transmitir la idea del protagonista, que podría sonar extraño e incomprensible de traducirse literalmente.

\section{- Memes de Internet}

Los fans son internautas expertos y están familiarizados con la jerga, la moda y los memes más populares del ámbito, que emplean con naturalidad en su traducción. Por ejemplo, 圆 (jiong) era un carácter poco usado en chino, pero 


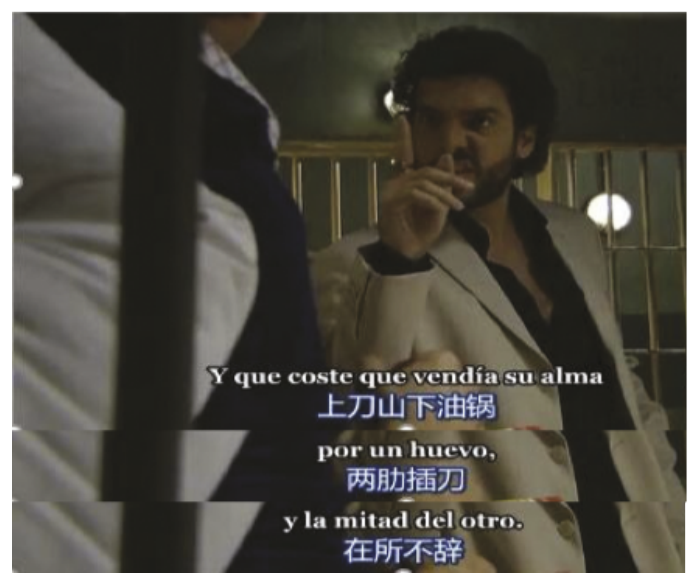

Figura 10. Uso de Chéngyǔ ofrecido por Moisés

en los últimos años se ha popularizado en la red para expresar el embarazo o la tristeza, a causa de su semejanza visual con una cara abatida. Este hecho concuerda con el contexto de incomodidad y difícil disimulación (Figura 11).

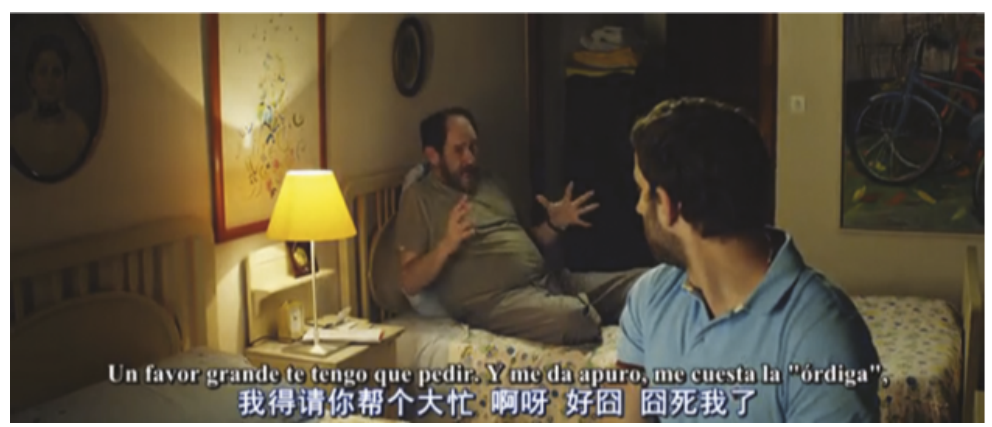

Figura 11. Uso de memes de Internet

\section{- Anotaciones}

Un rasgo que distingue el fansub de la subtitulación profesional es el uso de anotaciones (Ferrer, 2005), que suelen figurar entre paréntesis en el subtítulo o en la parte superior de la pantalla. Muchas series y películas buscan entretener al público con alusiones, juegos de palabras y referentes culturales (Tian, 2011), que resultan difíciles de traducir. Seleccionamos dos ejemplos donde se incluyen explicaciones: (1) nombres y localizaciones famosos en el mundo hispánico (ej. "Gordillo: futbolista español", "las Ramblas: paseo emblemático de Barcelona”); (2) el argumento, que además se asocia con un referente cultural (ej. "Moneda creado por el protagonista tomando el nombre de la Virgen de Montserrat en Catalunya”) (Figura 12). 


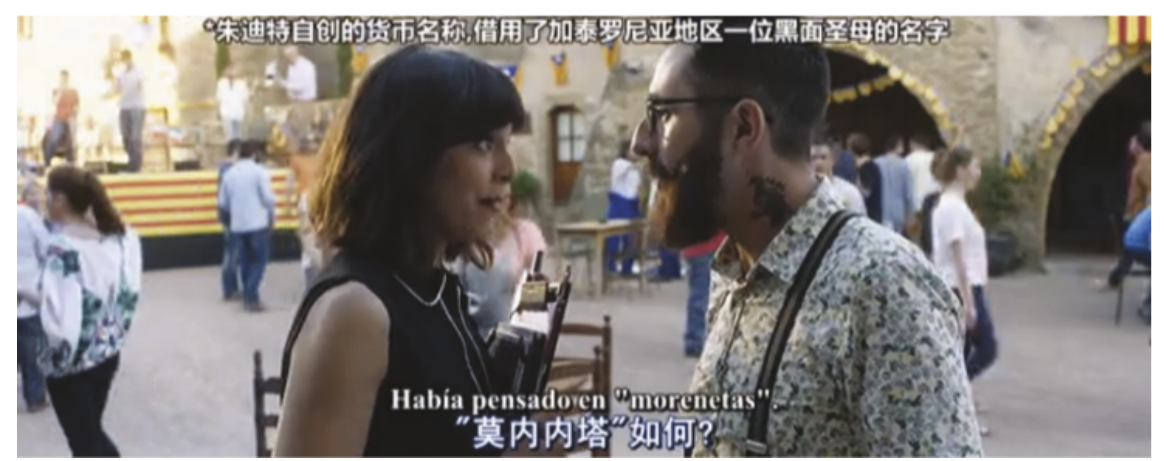

Figura 12. Uso de anotaciones

Por otra parte, el uso de las anotaciones difiere claramente de los requerimientos profesionales, que suelen omitir las explicaciones. Para situar a su público en el ambiente original de la serie, los fansubbers también pretenden que la tipografía de los subtítulos sea similar que el estilo de la escena (ej. emplear colores o efectos artísticos idénticos a los de la serie). Según Shin, los grupos más jóvenes a menudo usan una tipografía llamativa para sobresalir entre sus colegas, mientras que TB con los años ha superado este periodo y ahora busca poner acento en la calidad de los subtítulos, con un estilo claro y sencillo: los typesetters se ocupan de ajustar las letras españolas al cuerpo 12, Georgia y en negrita, y los caracteres chinos en el mismo tamaño, en Heiti y en color azul, como hemos observado en las capturas de pantalla (Figuras 10, 11 y 12).

\subsection{Errores}

Aunque los fansubbers manifiestan una fuerte competencia digital al apropiarse de distintas herramientas y recursos, no dejan de ser amateurs o estudiantes que cometen errores tanto por negligencia como por falta de conocimientos lingüísticos. Por ello los editores y el propio director se encargan de revisar todo el trabajo antes de pasarlo a posproducción. El director recopila los errores hallados con capturas de pantalla, que posteriormente presenta a la comunidad manteniendo el anonimato, en la reunión mensual. Estos son los errores más habituales de subtitulación:

\section{- Ortografía incorrecta}

Son frecuentes, a causa de descuidos al teclear o de deficiencias de comprensión. La primera situación se señala y muestra en público (ej. “^Quiero que sepias"), mientras que la segunda se comenta con mayor detalle, buscando soluciones. En Figura 13, la expresión fija "al fin y al cabo" se ha transcrito como "al final acabo", con lo cual la frase queda agramatical e incomprensible; 
para recuperarla, la directora Kiwi sugiere el uso de Google Search, tecleando parte de la locución y aprovechando el menú de autocompleción (Figura 3) que ayuda a obtener los vocablos correctos. Así un error corriente se aprovecha para presentar recursos informáticos que benefician la transcripción.

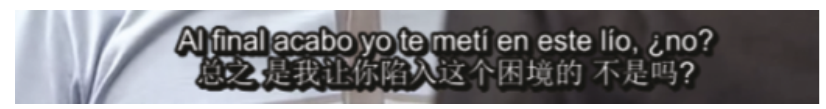

Figura 13. Ortografía incorrecta

\section{- Incumplimiento de las convenciones}

Las convenciones se establecen por y para el grupo (Apartado 4.1). Por ejemplo, cuando aparecen mensajes en el móvil o en papel, no pronunciados pero relacionados con el desarrollo de la historia, hay que añadirlos; también se deben eliminar las descripciones innecesarias en el CC, como descripciones del sonido. A veces los aprendices olvidan dejar una línea en blanco antes de empezar otra en el texto transcrito, lo cual dificulta luego su inserción en el vídeo. En tales casos se advierte repetidamente en el chat, para que los implicados tomen nota, sean fans recién incorporados o miembros antiguos.

Por otro lado, los fallos de traducción son más variados y frecuentes por varios motivos: (1) el registro coloquial, la conversación rápida o la complejidad y diversidad del español dificultan la comprensión del original; (2) las disimilitudes entre los dos idiomas, como la conjugación del verbo en español, que indica el tiempo, la persona e incluso el cambio de significado (ej. los reflexivos), dificultan la traducción; (3) los traductores provienen de lugares muy distintos del país, con experiencias diversas de aprendizaje del español, y con sus dialectos particulares, que deben evitarse en la expresión final. Estos son los errores más destacados:

\section{- Errores semánticos}

Son interpretaciones erróneas de palabras, causadas a menudo por la polisemia. Así, la acepción que se debe emplear no es necesariamente la más común, sino la que se ajusta mejor al contexto: "el árbol" pierde el significado básico de la planta (树 $s h u$ ) y se entiende por el cuadro genealógico (家谱 jiapu; Figura 14), mientras “la excedencia" se refiere al cese temporal (请假 qingjia) en lugar de la situación de estar “de sobra” (编外人员 bianwai renyuan; Figura 15).

- Errores fraseológicos

Las expresiones fijas y las frases hechas presentan grandes dificultades, dado que el significado pragmático no siempre deriva del contenido semántico de los componentes. Por ejemplo, el traductor (Figura 16) no se da cuenta de 


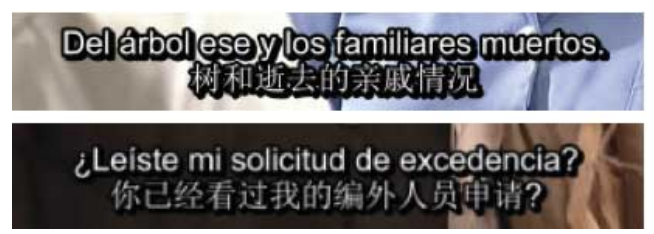

Figuras 14 y 15. Errores semánticos

la naturaleza idiomática de la frase “a tus espaldas” (背地里 beidi li), y elige una traducción literal con 骑在...背上 (qizai beishang) (“la acción de montar sobre la espalda”), lo cual se aleja del significado original. En Figura 17 se muestra una traducción aparentemente correcta en la que "bombo" equivale a “noticia bomba" (重磅消息 zhongbang xiaoxi), cuando en el original es “hacerle un bombo a una mujer” o “dejarla embarazada” (让她怀孕 rang ta huaiyun).

\section{te monte una fiesta a tus espaldas,} 他骑在你的背上办派对

\section{(37,365hora haz como si no supieras nada que el bombole has hechoa Paula.}

当然了现在你装作一点也不知道这个重磅消息给Paula带来了代公

Figuras 16 y 17. Errores fraseológicos

\section{- Errores sintácticos}

Este tipo de error se llama "encontrar el sujeto" en el grupo, y es una de las confusiones más habituales entre los aprendices sino hablantes de español. Las frecuentes elipsis de sujeto pronominal en español contrastan con la obligatoriedad de explicitar el sujeto del chino, por lo que los traductores tienen que ser capaces de reconocer el sujeto escondido en cada oración. No es una tarea fácil, dados los fenómenos lingüísticos frecuentes en español como la multiplicidad referencial de los verbos en $3^{\text {a }}$ persona, el caso de varios sujetos en el enunciado principal y la subordinada, o la oración impersonal. He aquí un ejemplo (Figura 18) en el que el fansubber se confunde por la alternancia de personas. En las dos frases antes y después de la conjunción, el sujeto debe ser yo y Martín respectivamente, pero en la traducción se entiende que en ambas es Vaquero, probablemente porque es el elemento que lidera la oración.

\section{- Errores gramaticales}

Otra diferencia fundamental entre las dos lenguas reside en la expresión del tiempo, que está marcado gramaticalmente sobre el verbo en español, pero 


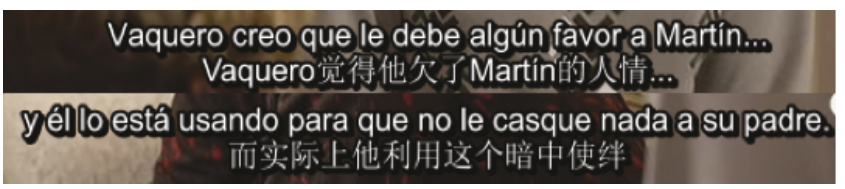

Figura 18. Error sintáctico

que en chino se formula con adverbios que no afectan al verbo. En algunas ocasiones el contexto ayuda a comprender el aspecto temporal, por lo que no hace falta añadir las partículas temporales correspondientes. Pero cuando el tiempo verbal es distinto del actual y transmite matices específicos, los adverbios juegan un papel relevante para reconstruir el significado completo en la traducción. Así, el pasado empleado en Figura 19 debería traducirse con adverbios como 曾经 (cengjing) (“antes”), y conlleva la implicatura de que ahora no es lo mismo. De esta forma, también se entenderá la siguiente escena, donde su interlocutor, al escuchar esto, le pregunta por el cambio. Si se traduce sin adverbios, o sea, en el indicativo original, parece un estado permanente, por lo que la pregunta no tendrá sentido y causará probablemente un malentendido.

\section{A mi también me pasaba igual. 我也是这样}

Figura 19. Error gramatical

Por último, destaca la meticulosa actividad de localizar los errores, ordenarlos, presentarlos y comentarlos a la comunidad, en las reuniones periódicas. En dichas reuniones es habitual que: (1) los miembros compartan recursos de comprensión oral y traducción para evitar los errores del mismo tipo; (2) algunos fans revelen su identidad admitiendo que cometieron determinados errores -y prometan prestar más atención-, y (3) otros fans justifiquen su perspectiva y discutan con los directores, de modo que el resultado queda pendiente de la consulta posterior de más referencias.

\section{Discusión}

Nuestro análisis de los fansubbers chinos muestra una comunidad en línea autorregulada, colaborativa, y empoderada por las nuevas tecnologías. Siguiendo las características de una comunidad de práctica (Wenger, 1998), los fans se afilian a la comunidad por un compromiso mutuo de aprender español, emprenden una 
empresa conjunta de subtitular series y películas hispánicas, y desarrollan un repertorio compartido de recursos multimodales (ej. rutinas, plataformas, artefactos, normas, etc.). Cada miembro empieza con una participación periférica, en la que ha de aprobar un test de acceso y un periodo de prueba para entrar en la comunidad (Zhang y Cassany, 2016), y progresivamente con las normas y prácticas y los estándares compartidos, derivados de las negociaciones diarias, asume una nueva identidad colectiva, más específica (subtitulador/director de TB), que implica mayor legitimidad, responsabilidad y motivación en la práctica social (Liu y de Seta, 2014).

Los fansubbers demuestran que más allá de proveedores alternativos de productos mediáticos, son agregadores y curadores de la materia prima (Kung, 2016), traductores amateurs que asimilan cualidades profesionales (i.e. petty producers; Abercrombie y Longhurst, 1998), y por último, si bien no menos importante, aprendices de español que pretenden mejorar su competencia lingüística. Apreciamos varias formas de promover el aprendizaje basado entre iguales (Ito et al., 2008), aprovechando la inteligencia colectiva del grupo (Lévy, 1997) y tratando de ampliar las habilidades lingüísticas y técnicas de todos los miembros (ej. elaborar tutoriales, reclutar y formar aprendices, señalar y comentar errores). Además, con las prácticas de subtitulación y traducción se fomenta el genre expertise (Dwyer, 2012; O’Hagan, 2008) en determinados géneros audiovisuales, imponiendo un estricto control de calidad, mediando tanto lo visual como lo verbal, lo contextual y lo intertextual (Ortabasi, 2007).

Documentamos con detalle cómo la red permite a los consumidores archivar, redistribuir y apropiarse de contenidos mediáticos de manera novedosa y poderosa (Jenkins, 2004), de acuerdo con sus intereses específicos. Así observamos la referencia estratégica de una variedad de online language resources (VazquezCalvo, Zhang, Pascual y Cassany, 2019), y el fenómeno de translanguaging con el portugués e inglés, lo cual otorga mejor calidad, eficiencia y flexibilidad al trabajo amateur. En el campo de los Nuevos Estudios de la Literacidad, estas prácticas letradas vernáculas (realizadas en ámbitos personales y privados) en la Web 2.0 son fuente de creatividad, invención y originalidad (Barton y Lee, 2013), y pueden ser aplicables a las prácticas dominantes (reguladas y prestigiadas por instituciones oficiales), por ejemplo, la formación de aprendices de ELE e incluso el aula de enseñanza formal.

En efecto, para los miembros que son estudiantes de español, la actividad de ocio ya se complementa con la del aula. Frente al registro formal que suelen protagonizar los libros de texto, las series populares les permiten conocer el habla en la vida cotidiana. En los chats de TB, uno de los temas más frecuentes es el uso de los dichos populares, la jerga estudiantil y el lenguaje vulgar (palabrotas, insultos, eufemismos, etc.). Un miembro se quejó de que solo después de ver las series se 
dio cuenta de lo coloquial y rápido que hablan los españoles. Al fin y al cabo, se debe considerar que, en muchos lugares de China, aún no es común hablar con hispanohablantes o acceder a grabaciones de conversaciones auténticas o equivalentes. En cambio, en la comunidad fansub, el aprendizaje no es una tarea individual, sino un recurso para desarrollar la capacidad expresiva, así como para crear y mantener relaciones sociales prestigiosas que influyan realmente en sus vidas (Thorne, 2008) (ej. algunos miembros de TB incluso establecen contactos offline visitando uno a otro).

En definitiva, creemos que el fansubbing, además de ser un ejemplo ilustrativo de las nuevas formas de la cultura participativa (Jenkins, 2006) y de sus novedosas implicaciones interculturales, destaca como recurso potencial para la didáctica de lenguas extranjeras, más allá del problema de delimitar los límites entre la actividad de aficionados y la enseñanza formal o de la dificultad de mediarlo empíricamente (Lakarnchua, 2015). Las prácticas descritas más arriba pueden servir como: (1) modelos y recursos de actuación en las situaciones de comprensión audiovisual de ELE en ámbitos privados; (2) tareas de aprendizaje en clases formales, o (3) ejemplo de aprendizaje informal de ELE a través de la afiliación a comunidades fan - de modo que los aprendices puedan desarrollar sus aficiones personales vinculadas a la lengua y la cultura española (Zhang y Cassany, 2019a, 2019b).

\section{Conclusiones}

En este estudio exploratorio y etnográfico, hemos documentado y analizado cómo los subtituladores de un grupo de fansub chino comprenden y traducen el español coloquial de las series de televisión hispánicas (objetivo general). Hemos descrito el proceso que sigue un miembro nuevo, que consiste en superar un test lingüístico de entrada y un periodo de prueba; acceder al chat del grupo; comprender y seguir documentos internos como tutoriales y colaborar en la producción de varios episodios. Así nos familiarizamos con la organización del grupo y su cadena de trabajo (objetivo específico 1 o OE 1), desde una perspectiva émica y participativa.

Con respecto al $\mathrm{OE}$ 2, analizamos las experiencias y estrategias que emplean dos informantes clave, Kiwi y Moisés, en las tareas de transcripción y traducción. Descubrimos que además de establecer criterios y procedimientos de colaboración, los fansubbers han desarrollado una serie de recursos (extra) lingüísticos y un mecanismo maduro de control de calidad de los subtítulos. Enlazando los datos en $\mathrm{OE} 1$ y 2 , discutimos hasta qué punto el fansubbing, como una práctica lingüística cooperativa emergente, sirve para el aprendizaje entre iguales en la nueva era digital ( $\mathrm{OE} 3$ ), además de constituir una contribución importante 
en varias disciplinas (traducción, enseñanza-aprendizaje de L2, comunicación audiovisual).

Finalmente, queda pendiente explorar las particularidades de los fansubbers chinos, que difieren de los grupos occidentales no solo en términos de idioma, productividad y organización, sino también en los criterios y valores de lo que se considera una buena traducción: mientras los fansubs chinos localizan el lenguaje, los occidentales lo extranjerizan intencionalmente conservando muchos elementos auténticos del original (Díaz-Cintas y Sánchez, 2006; Dwyer, 2012; O'Hagan, 2008, Shafirova y Cassany, 2019; Vazquez-Calvo, Zhang, Pascual y Cassany, 2019). En futuros trabajos esperamos profundizar en estos aspectos traductológicos y culturales, con el fin de entender mejor a nuestros participantes, jóvenes residentes digitales (White y Le Cornu, 2011) que se afilian a comunidades virtuales tan peculiares, desarrollan nuevas categorías de prácticas letradas fuera del aula y, finalmente, con ello, buscan construir, recrear y reivindicar su propia identidad digital.

\section{Bibliografía}

Abercrombie, N., y Longhurst, B. J. (1998). Audiences: A Sociological Theory of Performance and Imagination. Londres, Thousand Oaks y Nueva Delhi: SAGE Publications.

Androutsopoulos, J. (2013). Online data collection. En C. Mallinson, B. Childs y G. V. Herk (Eds.), Data collection in sociolinguistics: Methods and applications (pp. 236-250). Nueva York: Routledge.

Barton, D. (2007). Literacy: An introduction to the ecology of written language. Oxford: Blackwell Publisher.

Barton, D., y Lee, C. (2013). Language Online: Investigating Digital Texts and Practices. Milton Park, Abingdon, Oxon: Routledge. https://doi.org/10.4324/9780203552308

Boyko, D. (2012). A Study of Organizational Structure and Practices of Fansub Groups in China and Russia (Tesis de posgrado no publicada). Shih Hsin University, Taiwan.

Cáceres, P. (2003). Análisis cualitativo de contenido: una alternativa metodológica alcanzable. Psicoperspectivas. Individuo y Sociedad, 2(1), 53-82.

Casañ, J.C. (2016). Desarrollo de una prueba de comprensión audiovisual. MarcoELE, 22, $1-70$.

Díaz-Cintas, J., y Sánchez, P.M. (2006). Fansubs : Audiovisual Translation in an Amateur Environment. The Journal of Specialised Translation, 6, 37-52.

Dwyer, T. (2012). Fansub dreaming on ViKi: "Don't just watch but help when you are free." Translator, 18(2), 217-243. https://doi.org/10.1080/13556509.2012.10799509

Ferrer, M.R. (2005). Fansubs y scanlations: la influencia de los aficionados en los criterios profesionales. Puentes, 6, 27-44.

Fiske, J. (1992). The Cultural Economy of Fandom. En L.A. Lewis (Ed.), The Adoring Audience: Fan Culture and Popular Media (pp. 30-49). Londres y Nueva York: Routledge. 
Hamilton, M. (2000). Expanding the new literacy studies: using photographs to explore literacy as social practice. En D. Barton, M. Hamilton, y R. Ivanic (Eds.), Situated Literacies (pp. 16-35). Nueva York: Routledge.

He, T. (2014). Fansubs and Market Access of Foreign Audiovisual Products in China: The Copyright Predicament and the Use of No Action Policy. Oregon Review of International Law, 16 (abril), 307-346.

Hills, M. (2002). Fan Cultures. Londres: Routledge.

Hine, C. (2000). Virtual ethnography. Londres, Thousand Oaks, Nueva Delhi: Sage. https://doi.org/10.4135/9780857020277

Ito, M., Horst, H., Bittanti, M., Boyd, D., Herr-Stephenson, B., Lange, P. G., Pascoe, C. J. y Robinson, L. (2008). Living and learning with new media: Summary of findings from the digital youth project. Cambridge: MIT Press.

Jenkins, H. (1992). "Strangers No More, We Sing”: Filking and the Social Construction of the Science Fiction Fan Community. En L.A. Lewis (Ed.), The Adoring Audience: Fan Culture and Popular Media (pp. 208-236). Londres y Nueva York: Routledge.

Jenkins, H. (2004). The Cultural Logic of Media Convergence. International Journal of Cultural Studies, 7(1), 33-43. https://doi.org/10.1177/1367877904040603

Jenkins, H. (2006). Fans, bloggers, and gamers: exploring participatory culture. Nueva York: NYU Press.

Jenkins, H. (2013). The Cultural Context of Chinese Fandom: An Interview with Xiqing Zheng (part three). http://henryjenkins.org/2013/o2/the-cultural-context-of-chinese-fandom-aninterview-with-xiqing-zhengpart-three.html [Recuperado el 8 de septiembre de 2017]

Kung, S.-W. (2016). Audienceship and community of practice: an exploratory study of Chinese fansubbing communities. Asia Pacific Translation and Intercultural Studies, 3(3) 1-15. https://doi.org/10.1080/23306343.2016.1225329

Lakarnchua, O. (2015). Examining the potential of fansubbing as a language learning activity. Innovation in Language Learning and Teaching Society (2015), 1-13.

Lee, H.-K. (2011). Participatory Media Fandom: A Case Study of Anime Fansubbing. Media, Culture y Society, 33(8), 1131-1147. https://doi.org/10.1177/0163443711418271

Lévy, P. (1997). Collective Intelligence: Mankind's Emerging World in Cyberspace. Cambridge: Perseus.

Li, D. (2015). Amateur Translation and the Development of A Participatory Culture in China? A Netnographic Study of The Last Fantasy Fansubbing Group (tesis doctoral). Manchester: University of Manchester.

Liu, X., y de Seta, G. (2014). Chinese Fansub Groups as Communities of Practice. En P. Marolt y D. K. Herold (Eds.), China Online: Locating Society in Online Spaces (pp. 125-140). Londres y Nueva York: Routledge.

Martínez, E. (2010). Los Fansubs: El caso de traducciones (no tan) amateur. Tonos Digital, (20), 22.

O'Hagan, M. (2008). Fan translation networks: an accidental translator training environment? En J. Kearns (Ed.), Interpreter Training: Methods and Debates (pp. 158-183). Londres: Continuum.

Ortabasi, M. (2007). Indexing the Past: Visual Language and Translatability in Kon Satoshi'S Millennium Actress. Perspectives, 4(4), 278-291. https://doi.org/10.1080/09076760708669044

Pérez-González, L. (2007). Fansubbing Anime: Insights Into the "Butterfly Effect" of Globalisation on Audiovisual Translation. Perspectives, 14(4), 260-277.

https://doi.org/10.1080/09076760708669043 
Qiu, P. (2010). Audience Activity in the New Media Era: Chinese Fansubs of US TV Shows (Tesis de posgrado). University of Florida, US.

Shafirova, L., y Cassany, D. (2019). Bronies learning English in the digital wild. Language Learning \& Technology, 23(1), 127-144.

Stringer, E. T. (1999). Action Research. Thousand Oaks: Sage.

Thorne, S. L. (2008). Transcultural communication in open Internet environments and massively multiplayer online games. En S.S. Magnan (Ed.), Mediating Discourse Online (pp. 305-327). Ámsterdam: John Benjamins. https://doi.org/10.1075/aals.3.17tho

Tian, Y. (2011). Fansub Cyber Culture in China (Tesis de maestría). Washington: Georgetown University.

Tomaszkiewicz, T. (1993). Les opérations linguistiques qui sous-tendent le processus de soustitrage des films. Poznan: Adama Mickiewicza Uniwersytet Im.

Tonder, L. C. Van. (2015). Fansubbing and creative subtitling - How amateur approaches can help improve professional products. Recuperado de https://www.academia.edu/16564660 /Fansubbing_and_Creative_Subtitling_How_Amateur_Approaches_can_Help_Improve _Professional_Products, 20 de enero de 2017.

Valero-Porras, M. J., y Cassany, D. (2016). Traducción por fans para fans: organización y prácticas en una comunidad hispánica de scanlation. BiD: Textos Universitaris de Biblioteconomia I Documentació, (37). Recuperado de http://bid.ub.edu/es/37/cassany .htm, 20 de enero de 2017.

Vazquez-Calvo, B., Zhang, L.-T., Pascual, M., y Cassany, D. (2019). Language learning and fan translation of games, anime and fanfiction. Language Learning \& Technology, 23(1), 49-71.

Wang, F. (2014). Similarities and differences between fansub translation and traditional paperbased translation. Theory and Practice in Language Studies, 4(9), 1904-1911. https://doi.org/10.4304/tpls.4.9.1904-1911

Wenger, E. (1998). Communities of Practice: Learning, Meaning, and Identity. Cambridge: Cambridge University Press. https://doi.org/10.1017/CBO9780511803932

White, D.S., y Le Cornu, A. (2011). Vistiors and residents: A new typology for online engagement. First Monday, 16(9). Recuperado de http://firstmonday.org/ojs/index.php /fm/article/view/3171/3049, 20 de enero de 2017.

Xiu-xing, C.A.I. (2015). Fansubbing Humor: A Mainland China case study. Journalism and Mass Communication, 5(9), 435-453.

Zhang, L.T., y Cassany, D. (2016). Fansubbing del español al chino: organización, roles y normas en la escritura colaborativa, BiD: textos universitaris de biblioteconomia $i$ documentació, (37), Recuperado de http://bid.ub.edu/es/37/tian.htm, 7 de diciembre de 2017.

Zhang, L.-T. \& Cassany, D. (2019a). El fenómeno «danmu» y la participación mediática: Comprensión intercultural y aprendizaje de lenguas a través de «El Ministerio del Tiempo» [The "danmu" phenomenon and media participation: intercultural understanding and language learning through "The Ministry of Time"]. Comunicar, 58, 19-29. https://doi.org/10.3916/C58-2019-02

Zhang, L. T. \& Cassany, D. (2019b). 'Is it always so fast?': Chinese perceptions of Spanish through danmu video comments'. Spanish in Context, 16(2), 217-242. https://doi.org/10.1075/sic.00035.zha

Zhang, X. (2013). Fansubbing in China. MultiLingual, Julio-Agosto, 30-37. 


\title{
Practices on audiovisual comprehension and Spanish to Chinese translation in a fansub community
}

\begin{abstract}
We document and analyze a Chinese fansub community, which translates and subtitles Hispanic series and films, exploring the resources and strategies they use to understand and transcribe Spanish and translate it into Chinese. With virtual ethnography (Hine, 200o), combining participant observation, in-depth interviews and content analysis, the results show a hierarchical community with rules regulating the collaborative processe of writing and translation, including the use of sophisticated multimodal strategies (creative use of technical and language resources and websites, translanguaging practices). The community also develops its own criteria for what is a good translation, adopting a serious learner's role and attitude before mistakes. These practices exemplify other relevant characteristics of digital communities (fan productivity, cultural mediation, audiovisual and amateur translation) and offer interesting resources that could be applied to the formal teaching of $\mathrm{L} 2$.
\end{abstract}

Keywords: fansub, audiovisual comprehension and translation, online language resources, translanguaging, Spanish as a foreign language

\section{Dirección para la correspondencia}

Leticia Tian Zhang

Universitat Pompeu Fabra

Roc Boronat, 138, despacho 53.212

o8018 Barcelona

España

leticiatian.zhang@upf.edu

\section{Información de coautores}

Daniel Cassany

Universitat Pompeu Fabra

daniel.cassany@upf.edu 